\title{
EXPERIMENTALLY MEASUREMENT AND ANALYSIS OF STRESS UNDER FOUNDATION SLAB
}

\author{
*Marek MOHYLA ${ }^{1}$, Karel VOJTASIK ${ }^{1}$, Martin STOLARIK ${ }^{1}$, Miroslav PINKA ${ }^{1}$ and Hynek LAHUTA ${ }^{1}$ \\ ${ }^{1}$ Faculty of Civil Engineering, VSB - Technical University of Ostrava, Ostrava, Czech Republic
}

*Corresponding Author, Received: 13 May 2016, Revised: 26 July 2016, Accepted: 15 Dec. 2016

\begin{abstract}
Understanding of a load redistribution into subsoil below building foundation is an important knowledge for reliable design and its economy too. The article presents the results of a physical model of a foundation slab and its interaction with the subsoil. The interactions were investigated comprehensively by monitoring the developments of stress in the subsoil and foundation slab settlement during its loading. The load acting on the foundation was applied by strutting the hydraulic press against heavy steel frame which was established by the Department of Building Structures, Faculty of Civil Engineering of VSB -TU Ostrava for this purpose. The preparatory phase of the present experiment involved the homogenization of soil during which trio pressure cells in three horizons were gradually fitted. The quality of homogenization was checked on an ongoing basis through field tests: dynamic penetration load test, dynamic plate load test and seismic measurement of foundation slab response. Finally, the homogenized soil was subjected to mechanical analysis to determine the strength and deformation parameters for basic Mohr-Coulomb constitutive model.
\end{abstract}

Keywords: Physical model, foundation slab, foundation-subsoil interaction, subsoil pressure

\section{INTRODUCTION}

Surface foundation slab transfers the load from the building into the subsoil (or foundation environment). The load is transferred into the subsoil by contact stress on the physical surface interface between the foundation slab and the subsoil. From this interface, stress extends further into the subsoil and the stress increment in the subsoil caused by the load is progressively reduced with increasing distance from the physical interface. The extent and value of stress increments below the foundation in the subsoil caused by the load are determined by the appropriate analytical methods of force balance, and deformation or numerical methods. Direct stress measurements are only carried out on the horizon of the foundation base in the case of major building structures [1]-[3]. Experimental measurements on the horizons below the foundation base were conducted rarely based on in situ physical models at 1:1 scale on the original subsoil [4], [5]. So far, the calculation of stress values at different subsoil horizons below the foundation has not been verified at points such as the centre of gravity, characteristic point, edge and corner of the foundation slab surface. The installation of measuring pressure cells into the original subsoil above each other at different horizons is impossible without disturbing the subsoil structure, thereby affecting measurement results. Installing pressure cells distributed across the subsoil in the desired scheme is only possible if the subsoil is artificially created, where pressure cells may be installed gradually in the course of subsoil creation. This paper deals with the direct experimental measurement of stress below the foundation slab, as this measurement was performed on a real foundation built on artificial subsoil. The paper documents in detail the preparation and verification of the quality of artificial subsoil, a system of measuring pressure cells installed at three horizons, conditions during measurement, the recorded data, and data processing.

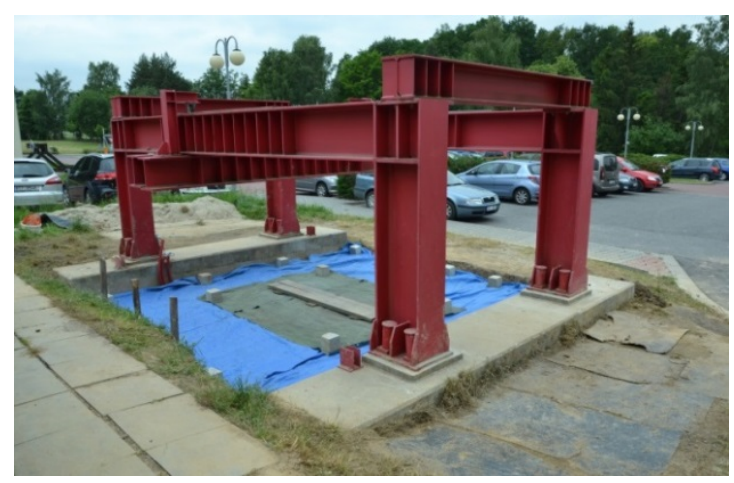

Fig. 1 Heavy steel test frame

\section{EQUIPMENT}

The Faculty of Civil Engineering, VSB-TU Ostrava has an external heavy steel test frame used to conduct experiments on building structural elements. Fig. 1 shows a photograph of the test frame. The steel frame was designed by the Department of Building structures in cooperation 
with Department of Geotechnics and Underground Engineering. The aboveground part of the test frame is a steel frame assembled from steel I beams.

The underground part consists of two foundation wall strips which are, additionally, anchored by $5 \mathrm{~m}$ long steel tube micro-piles $(89 / 10 \mathrm{~mm})$. Each of the wall strips is anchored into the subsoil by five micro-piles. Three of them are vertical and the two remaining ones are inclined at both ends of the wall strip.

The total bearing capacity of the micro-piles in tensile load is $1 \mathrm{MN}$. A detailed diagram of the test frame structure is shown in Fig. 2.

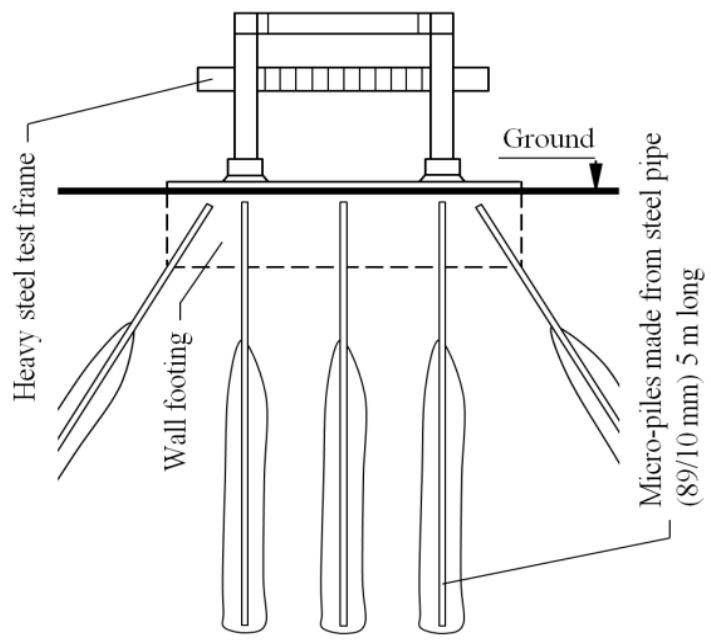

Fig. 2 Structure scheme of the heavy steel test frame

\section{PREPARATION OF ARTIFICIAL SUBSOIL}

For the progress of the experiment to be successful, it was desirable that the subsoil influenced by interactions with the experimental model foundation slab showed homogeneous properties (descriptive, stress and strain properties). Partial results of experiments for example [6], [7] and subsequent field tests, however, showed that the subsoil does not show such homogenous properties. The inhomogeneity of subsoil properties was due to the geological profile in the region of interest [8] and the technology used to build the test frame foundations. These foundations are monolithic and have been built in a sloped excavation by depositing concrete into the formwork. Backfill was built using the original soil; however, it has not been compacted to the original state, which had the largest impact on the inhomogeneity of the environment. Fig. 3 shows the heterogeneity of the original soil; the wall of the excavation contains the original subsoil and fills, and the side sections next to the concrete foundations contain backfill of the sloped excavation from the time the test frame foundations were built.

Based on the identified circumstances, homogenization was performed as follows:

Complete excavation of soil from under the test frame, which was defined by the position of the frame test foundation and the depth of the test frame foundation base (Fig. 1).

Backfill: excavated soil was gradually (in layers with a thickness of up to $15 \mathrm{~cm}$ ) deposited back into space under the test frame. The backfill was performed manually, with the stochastic selection of sampling points from the excavated soil. It was then evenly spread over the entire area under the test frame. The thickness of layers was modified as necessary depending on the desired location horizon of pressure cells.

Compaction: compaction was performed using vibration rammer with compaction force of $12.0 \mathrm{kN}$ (Fig. 3). The quality of compacting of each layer was continuously verified by a light dynamic plate (impact modulus of elasticity $E_{v d}[\mathrm{MPa}]$ ). In the case of surface areas with lower parameters, the area was re-compacted and verified.

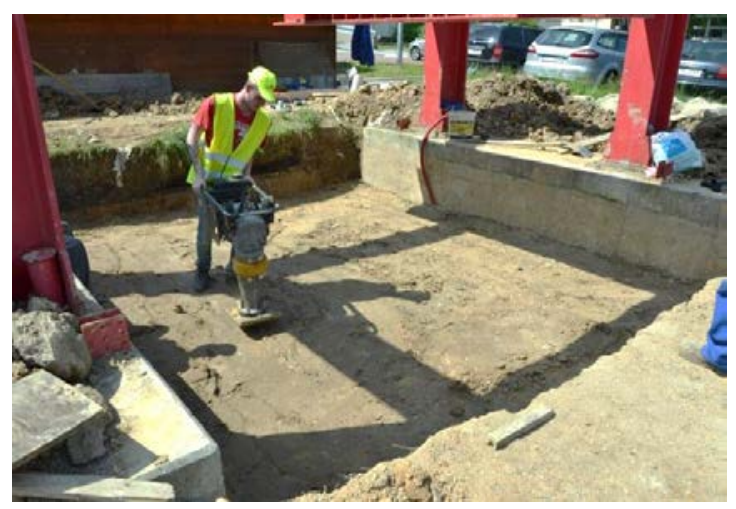

Fig. 3 Completion of sub-layers by compaction

As a result of the above manner to perform the backfill, it was possible to build a foundation environment with quasihomogeneous layers exhibiting homogeneous properties, especially in the horizontal plane. This led to the creation of an environment with the vertical direction of anisotropy. To ensure a homogeneous isotropic subsoil, the excavated soil (approx. 20 $\mathrm{m}^{3}$ ) would have to be homogenized as a one part. Given that complete homogenization would be time consuming and due to the absence of the required technology (machines), homogenization of the foundation subsoil was performed as described above. The layout of the experiment and the method of applying load on the experimental foundation allowed the above method of homogenization to be used. 


\subsection{Installation of pressure cells}

As part of the backfill of the homogenized subsoil, pressure cells (Geokon, Model 4800 and 4810) were continuously fitted, successively in two depth horizons $(-0.800 \mathrm{~m},-0.350 \mathrm{~m})$ below the future foundation base and in the foundation base $(0.000 \mathrm{~m})$. The cells were fitted at three locations in each of the horizons: the centre, the centre of the edge and corner of the experimental foundation slab. The cells in the centre of the edge and corner of the foundation slab were placed $5 \mathrm{~cm}$ from the edge of the foundation slab, i.e. $0.835 \mathrm{~m}$ from the centre of the slab. A total of 9 pressure cells in three horizons and three vertical axes were fitted (fig. 4). The placement of the pressure cells in various depth horizons was derived by comparing the nominal bearing capacity of the pressure cells used $(2 \times 170 \mathrm{kPa}, 6 \times 350 \mathrm{kPa}, 1 \times 700 \mathrm{kPa})$ and the expected developments of stresses in the subsoil beneath the loaded experimental foundation according to the theory of elastic half-space defined by Boussinesq.

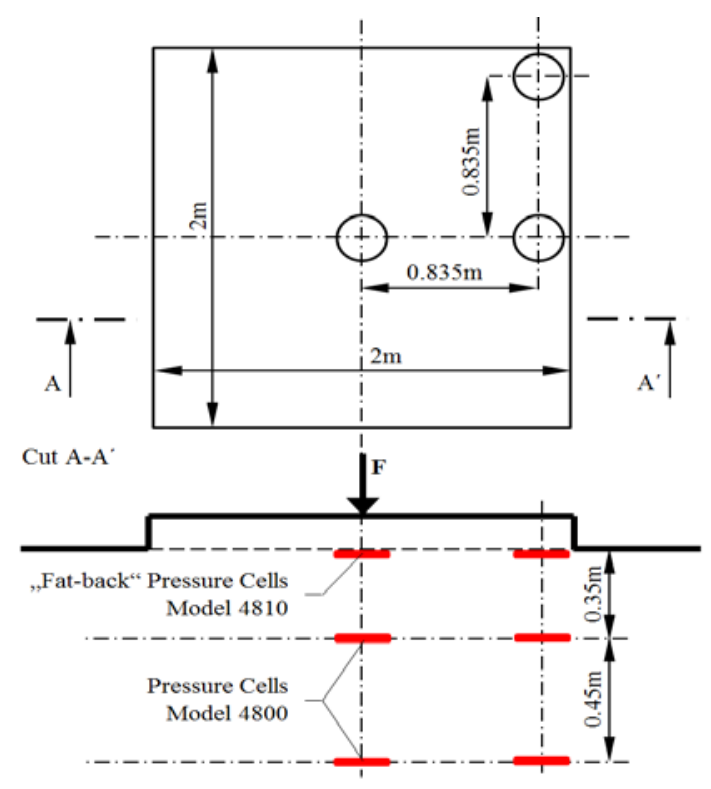

Fig. 4 Layout of pressure cells

The thickness of backfill layers was modified as necessary always to have the pressure cells placed in an additional groove with a depth of about $100 \mathrm{~mm}$ in the freshly compacted layer. The bottom of the groove was levelled off with a steel scraper, filling up with soil was not accepted due to the potential creation of a local site with a different degree of compaction. Although the risk of a possible occurrence of stone or boulder was eliminated during homogenization, the site where the pressure cell was placed was subjected to a subjective penetration check by a thin steel needle to a depth of about $5 \mathrm{~cm}$ at 9 locations. The fitted pressure cell was gradually covered by homogenized soil and continuously compacted up to the level of the surface of the currently compacted layer. When compacting the backfill of the cell, the emphasis was placed on keeping a consistent degree of compaction with the surrounding environment. Backfill with sand was excluded due to the different strain parameters compared with the original soil. This could negatively affect the registered stress in the pressure cell. The foundation base was fitted with cells (fat-back pressure cell, type 4810) intended for contact with the soil and the slab. The side of the cell touching the slab is reinforced with a steel plate due to specific developments in the stress on the interface between the soil and the slab. The method of mounting pressure cells was adapted to the layout conditions under the foundation of the present experiment, while respecting the recommendations made by the pressure cell manufacturer.

Pressure cells intended for the monitoring of the stress in the soil environment record stress, which is calculated as the sum of total stress $(\sigma)$ and atmospheric pressure (P). Effective stress $\left(\sigma^{\prime}\right)$ can be calculated using the following Terzaghi's Eq. (1), provided that the place where the pressure cell is located is fitted with a piezometer for monitoring pore pressures $(\mathrm{u})$, and total stress $(\sigma)$ is free from the influence of atmospheric pressure:

$\sigma^{\prime}=\sigma-u$

The measured values are affected by numerous factors distorting the results, some of which can be corrected (from a temperature of the atmospheric pressure). One of the factors which, however, cannot be affected, is the ratio of strain parameters (stiffness) of the pressure cell and the surrounding soil environment, which should ideally be identical. The pressure cell with higher stiffness as compared to the soil environment registers higher values of stress which do not correspond to the geostatic stress including any incremental stress due to the load. Moreover, the situation is complicated by the different stiffness of the pressure cell itself, which has a substantially higher circumferential stiffness than surface stiffness. Generally, there is a direct correlation between the thickness of the pressure cell and the degree to which pressure is affected due to the different ratios of elastic modulus of the pressure cell and the environment. The thinner the pressure cell, the less the measurement is affected by error due to differences in strain parameters of the cell and the environment.

The technology used to fit the pressure cells into the soil environment also affects the measurement significantly. The environment 
around the pressure cells must be homogeneous and evenly compacted. Pressure readings on cells may show lower stress values than in the case where the soil environment near the cell is less compacted. The cell does not register all stresses due to the non-compacted soil, which becomes consolidated during loading. Therefore, stress is transferred to the vicinity of the cell and the stress tensor above the pressure cell takes the form of an arch. Conversely, if the immediate vicinity around the cell is compacted more than the surrounding environment, this leads to stress becoming concentrated in this region; consequently, the cell registers a higher stress which does not correspond to geostatic stress including any incremental stress due to the load.

\subsection{Quality control concerning the execution of finished subsoil}

As part of the preparatory work before and during the subsoil finishing, field tests were conducted which were used to optimize and control the work [9]. Measurements carried out during and after homogenization were compared with the reference measurement conducted prior to homogenization. The following in-situ tests were used:

- dynamic penetration load test,

- dynamic plate load test,

- $\quad$ seismic measurement of foundation slab response.

The aim of the dynamic penetration load tests was to determine the resistance of the soil before and after in-situ homogenization to cone penetration. The cone was driven in using "constant force" applied by a ram with a known weight $(\mathrm{Q}=10 \mathrm{~kg})$ and a constant drop height $(\mathrm{h}=0.5 \mathrm{~m})$. The penetration resistance was then defined as the number of strokes needed to drive the cone down by the required depth and converted to dynamic resistance $\mathrm{q}_{\mathrm{dyn}}[\mathrm{MPa}]$ according to the recommendations of ISSMFE Eq. (2). The calculation also includes the following parameters $\mathrm{q}[\mathrm{kg}]$ - weight of compound rod, anvil and the tip for the appropriate depth, A $\left[\mathrm{m}^{2}\right]$ - transverse cross-section of the tip and $\mathrm{s}$ [m] - driving the tip with one stroke, which was determined as the proportion of prescribed depth for driving the cone (for the Czech Republic equivalent to N10=0.1m) and the number of strokes needed to drive the rod down by this depth.

$q_{\text {dyn }}=(2 \cdot Q \cdot h) /((Q+q) \cdot A \cdot s)$

Dynamic penetration load test was carried out in four selected locations before and after homogenization. The results are shown in Fig. 5. The results show that soil resistance to penetration of the penetration probe tip was very low; however, after homogenization the results are more consistent. The test was carried out always in a depth where undisrupted original subsoil with homogeneous properties was detected. To obtain more objective results, it would be necessary to generate more penetration tests because of generally greater sensitivity of the actual test to local heterogeneity of the environment.

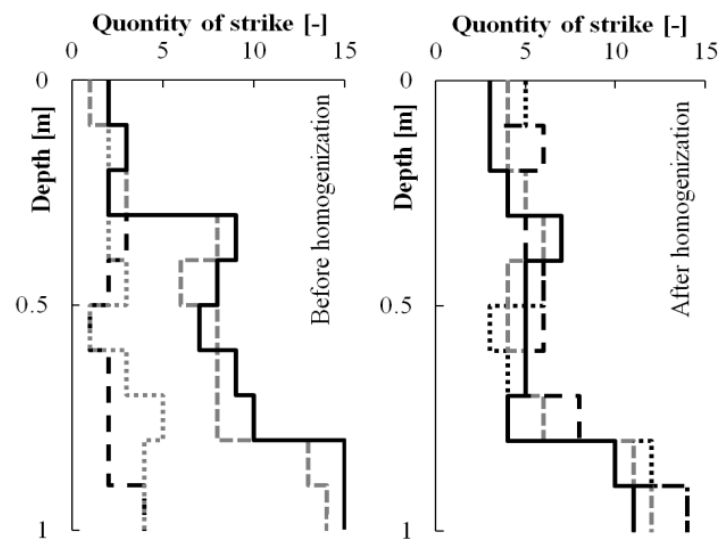

Fig. 5 Results of dynamic penetration load test

Dynamic plate load test generally belong to non-destructive forms of testing. The surface of the test environment was loaded with impact pulse in the form of approximately half of a sinusoid, which was caused by a weight falling on a circular plate with a diameter of $0.3 \mathrm{~m}$. The fall of the ram on the circular load plate through a damping system caused a deflection of the surface of the environment being measured.

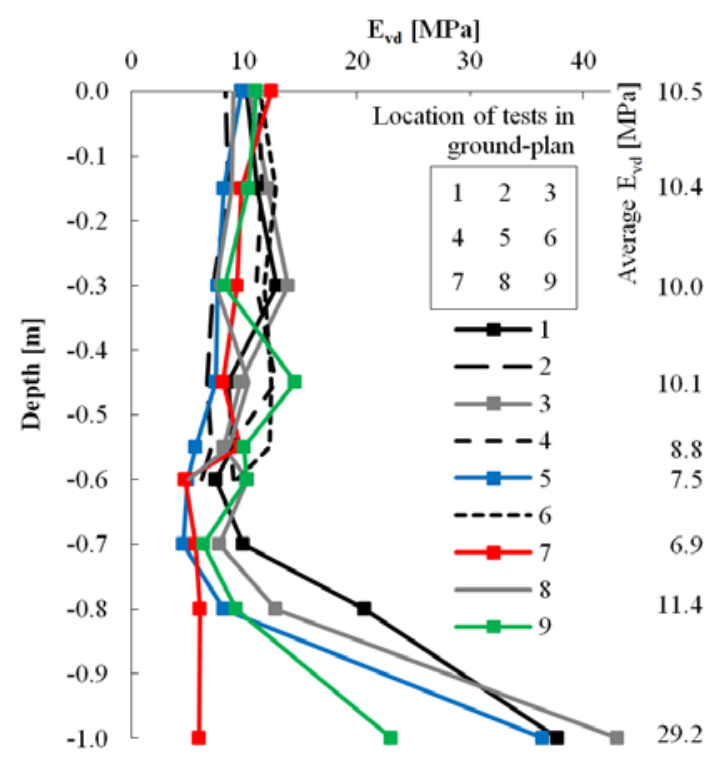

Fig. 6 Results of light dynamic plate

The evaluation of the deflections allowed 
physical and mechanical properties of the environment (impact deformation modulus $E_{\mathrm{vd}}$ $[\mathrm{MPa}])$ to be obtained.

During the homogenization, this test was used to determine the quality of compaction of each layer. In the horizon $-1.00 \mathrm{~m}$ to $-0.60 \mathrm{~m}$, a test was conducted in five locations; in the horizon $-0.60 \mathrm{~m}$ to the foundation layer $(0.00 \mathrm{~m})$ the test was conducted more frequently (in 9 locations). Fig. 6 graphically summarizes the results, which evidently show that the gradual backfilling and its compaction leads to an increased consistency of properties as well as to an increase in the average value of the deformation impact modulus $\mathrm{E}_{\mathrm{vd}}$.

To verify the homogenization of the subsoil and the quality of compaction after soil change, seismic measurement of dynamic response of the foundation slab was also used. For mutual comparison, one experiment was conducted on the concrete slab before the subsoil change, and the same experiment was then also repeated on the slab after the change. The method selected for the processing of measurement results was the creation of wave fields across the surface of the slab. Similar evaluations were presented in the papers [10]. The source of the dynamic stress, the calibrated strike, was placed at a distance of 1meter from the slab. Based on the measured values of the maximum oscillation amplitude on sensors S1 to S6, wave fields over the surface of the concrete slab were created for three measurement directions, i.e. vertical, horizontal radial and horizontal transversal directions. Wave field were created using Voxler3 and the inverse distance method (IDW). Due to changes of deformation properties of soil during homogenization that affected the propagation of vibrations through the environment and their transfer to the slab, it was necessary to establish a relative percentage assessment which will respect to a greater extent the trend of propagation of vibration in the concrete slab.

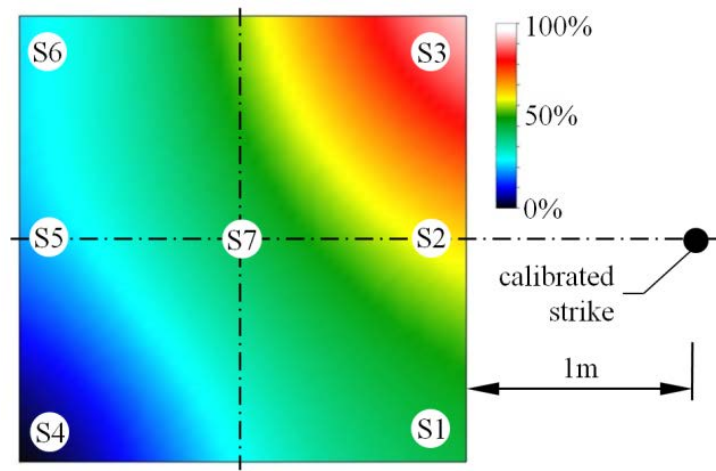

Fig. 7 Wave field for horizontal transversal direction - before homogenization

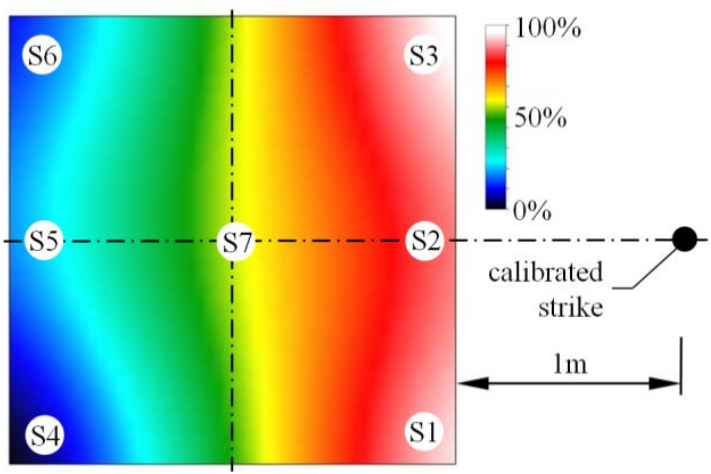

Fig. 8 Wave field for horizontal transversal direction - after homogenization

Examples of results are presented in Figs. 7 and 8, showing wave field before and after homogenization for horizontal transversal direction.

The aim of the in-situ tests was mainly to ensure quality monitoring of soil treatment (homogenization). Due to the selected form of homogenization, which helped to achieve a subsoil with a vertical axis of anisotropy, this involved qualitative evaluation of properties in the horizontal direction. These tests did not concern the achievement of the defined values. Direct methods of compaction quality control, e.g. according to proctor the combination of Proctor compaction test and membrane densitometer could not be employed due to time intensity and layout complexity.

\section{DESCRIPTION OF THE EXPERIMENT}

The design of experimental slab was developed by the Department of Building Structures and was based on the results of existing experiments [11], [12], [13] and the layout constraints of the test frame structure. Larger sizes of the experimental basis would lead to the interaction between the foundation and the subsoil being affected by the existing test frame foundations. A model foundation slab was made of plain concrete of $2 \times 2 \mathrm{~m}$ and a thickness of $0.2 \mathrm{~m}$. The class of the concrete according to the compressive strength was C35/45. During slab casting, three samples were made for later analysis of strain parameters (table 1).

Table 1 Foundation slab properties

\begin{tabular}{ccccc}
\hline $\begin{array}{c}\mathrm{f}_{\mathrm{ck}, \mathrm{cyl}} \\
{\left[\mathrm{N} / \mathrm{mm}^{2}\right]}\end{array}$ & $\begin{array}{c}\mathrm{f}_{\mathrm{ck}, \mathrm{cube}} \\
{\left[\mathrm{N} / \mathrm{mm}^{2}\right]}\end{array}$ & \multicolumn{2}{c}{ Young's modulus $[\mathrm{GPa}]$} \\
\hline 35 & 45 & 29 & 30,5 & 28 \\
\hline
\end{tabular}

The load was applied to the foundation slab by means of a hydraulic press leaning against the test frame structure. Loading took place in several 
steps, each taken every 0.5hours. Each loading step was about $80 \mathrm{kN}$, with a total of 7 steps taken, i.e. the slab was subjected to a theoretical maximum load of about $600 \mathrm{kNm}$. These load values could not be achieved with total precision due to gross dosing of the press used. The real values of the load in individual steps and are summarized in Table 2. Each loading step involved the following steps:

the increase in load $\Delta \mathrm{F}=80 \mathrm{kN}$ (the load increment was achieved in about 1 minute), stress readings on pressure cells made immediately after loading (about 3 minutes),

- stress readings on pressure cells made before terminating the loading step (about 3 minutes),

- $\quad$ the increase in load in the next step.

The experimental foundation was loaded by the proposed scheme regardless of any defects occurring during loading. Continuously with measuring, temperatures were recorded on individual pressure cells, including atmospheric pressure, which was later used to calibrate the measured data. Also, settlement of the foundation slab was recorded using electronic linear path sensors. Pore pressures were not recorded.

Hydraulic equipment used by the implementation team during the experiment did not allow keeping constant pressure during one loading step. As a result of the above, the pressure in the hydraulic load decreased depending on the subsoil being strained. Therefore, the experimental slab was not subjected to loading by constant force within one loading step.

Table 2 Load steps of experimental slab

\begin{tabular}{cccccccc}
\hline Step & 1 & 2 & 3 & 4 & 5 & 6 & 7 \\
\hline $\begin{array}{c}\text { Load } \\
{[\mathbf{k N}]}\end{array}$ & 82 & 166 & 244 & 310 & 385 & 471 & 616 \\
\hline
\end{tabular}

During the period from subsoil homogenization until the actual experiment, the test frame was covered with a tent which prevented potential saturation of the subsoil as a result of precipitation. The groundwater level during the experiment was also not encountered; it can be thus assumed that the environment was not $100 \%$ saturated. The load test on the described experiment was performed around 4 months after the subsoil homogenization. During this period, dissipation of potential local pore pressures occurred and humidity anisotropy with defining vertical axis was created.

\section{DISCUSSION}

The course of the interaction between the foundation slab and the subsoil is primarily affected by the dimensions of the foundation and the ratio of strain parameters of the foundation and the subsoil. The experimental foundation slab which, at this stage of research, was not reinforced had the character of a pliable foundation, where uneven settlement can be expected. As a consequence of low stiffness of the foundation slab, loading was accompanied by uneven settlement and uplift of the corners above the ground, and a gradual reduction in the contact area between the foundation and the subsoil. Due to the low tensile strength of concrete (approximately 10x less than the compressive strength), very soon (in the third step) the first tensile cracks emerged, developing from the foundation base (at a load of approximately $250 \mathrm{kN}$ ). During the subsequent loading step, the cracks spread over the entire height of the foundation slab, resulting in a significant reduction of the contact area between the foundation and the subsoil. The load of the slab redistributed to a smaller area then resulted in a significant increase in stress in this reduced contact area between the foundation and the subsoil.

The following figures show the results of monitoring total vertical pressure on cells located in the subsoil under the experimental foundation slab according to Fig. 4. The pressure distribution diagrams are already free from the influence of atmospheric pressure, temperature and stress due to the weight of the overlying strata, i.e. they are total incremental stresses developed in the subsoil only due to load. The results are systematically divided into diagrams according to the depth location of the pressure cells and their horizontal position about the foundation slab.

Fig. $9(\mathrm{z}=0.00 \mathrm{~m})$ summarizes the progress in stress acting on the three cells located in the foundation base. The solid line characterizes stress below the middle, where a significant increase in stress during the third loading step is evident (1.5hours). The cell located under the corner simultaneously stopped recording stress due to the uplift of the corners of the experimental slab described above.

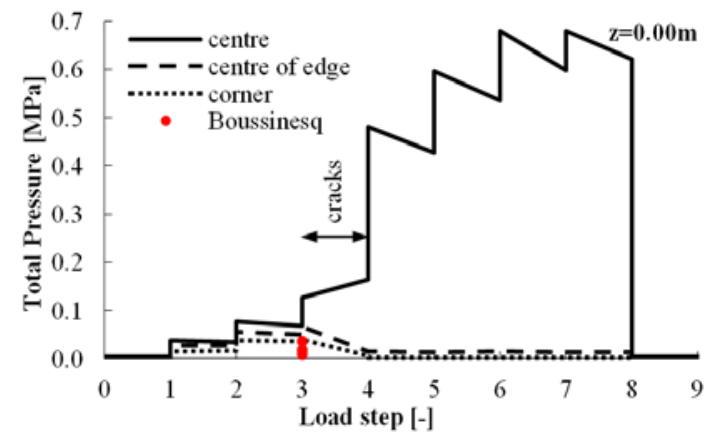

Fig. 9 Total pressures in foundation base during loading 


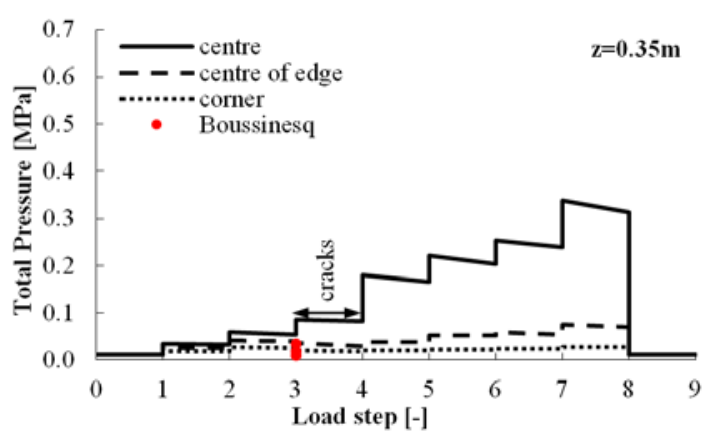

Fig. 10 Total pressures in horizon -0.35 during loading

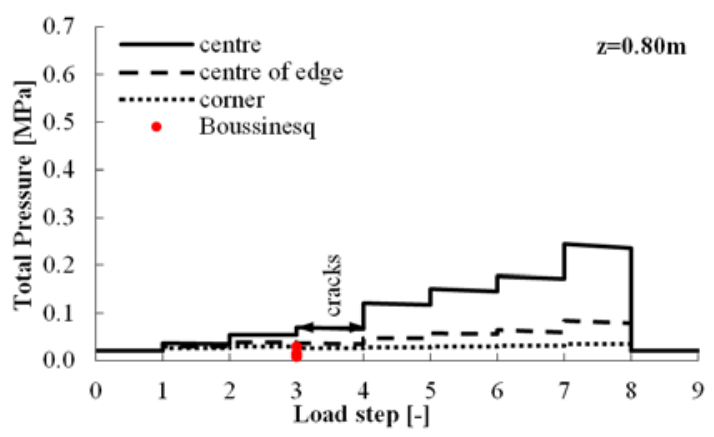

Fig. 11 Total pressures in horizon -0.80 during loading

Figs. 10 and 11 presents the results of the trio cells located at a depth of $0.35 \mathrm{~m}$ and $0.80 \mathrm{~m}$, respectively. Here, the qualitative development of stress is similar, differing only in absolute pressure values. Even at these depths, a sharp rise in stress is evident, due to the reduction of the foundation base.

The red dot in diagrams presents the stress for loading step before the rupture of the foundation slab, determined based on the theory of elastic half-space (Boussinesq).

\section{CONCLUSION}

The paper aimed to present the results of a physical model, including preparatory work involving the preparation of subsoil (homogenization) and mounting pressure cells to monitor total stress. In particular, stress redistribution in the subsoil below the loaded experimental foundation slab was monitored. During these activities, several facts have been confirmed, which should be summarized in the conclusion.

The importance of the correct positioning of the pressure cell in the soil environment proved to be crucial. It is essential that material and state homogeneity of the immediate environment around the cell is observed when the pressure cells are being fitted. Failure to observe this will significantly affect the monitoring of total stress in the subsoil. The ratio of strain parameters of pressure cells and subsoil also has a significant influence. Generally, the stiffer the cell compared to the soil environment, the higher total stress it reads. The above information must be observed when fitting pressure cells as well as when interpreting the readings.

The readings of incremental pressures in the selected loading step were evaluated and compared with the readings based on the elastic half-space theory (Boussinesq). The above comparison was performed using the loading step before the disruption of the experimental foundation slab. After the disruption of the experimental basis, the contact area at the foundation base was reduced, which greatly affected the interaction between the foundation slab and the subsoil. It should be borne in mind that the theory does not allow taking account of the stiffness of the foundation slab, which significantly affects the settlement and the redistribution of stress in the subsoil. The comparison must, therefore, be considered as indicative.

In the course of the experiment, there were a few questions that will need to be answered during further research in this area. The physical model will be extended to include the possible influence of groundwater level with a possible modification of its depth. For these purposes, it will be necessary to increase the permeability of the subsoil. To increase the permeability by e.g. mixing the original soil with sand, it would be necessary to add an amount of sand larger than the volume of the original soil, which would inter alia, increase the strain parameters of the subsoil. This is not desirable due to changes in relative stiffness in the foundation-subsoil system. The effort to increase the settlement of the experimental foundation as a result of a load applied to it could, therefore, lead to the bearing capacity of the test frame being exceeded. Another problem involves the fact that controlled saturation of the subsoil is time-consuming and that it is affected by capillary elevation, which is problematic. One possible solution to that situation is to create a sandwich of layers of the original soil (approx. $0.20 \mathrm{~m}$ thick) and a drainage layer (approx. 0.05m thick). Any internal erosion of the original soil is prevented by inserting a non-woven geotextile beneath the drainage layer. Such a layer structure would allow changing the groundwater level in $0.25 \mathrm{~m}$ increments in a relatively short period thanks to a significantly shortened drainage path, while preserving the strain parameters of the original subsoil. 


\section{ACKNOWLEDGEMENTS}

This outcome has been achieved with the financial support of the project GACR No. 16-08937S „State of stress and strain of fiber reinforced composites in interaction with the soil environment“. In this undertaking, theoretical results gained by the conceptual development of research, development, and innovations for 2015 at the VSB-Technical University of Ostrava (granted by the Ministry of Education, Youths and Sports of the Czech Republic) were partially exploited.

\section{REFERENCES}

[1] Milev N., Kostov V. "Monitoring of the foundation of an existing RC building and some modelling approaches“, NZSEE Conference 2015, Wellington, New Zealand, pp. 199-206.

[2] Mendoza M. J., Rufiar M., Ibarra E., Mendoza S.A. "Performance of a pioneer foundation of the skirt type for the Metro-Line 12 overpass“, Proceedings of the 18th International Conference on Soil Mechanics and Geotechnical Engineering, Paris 2013.

[3] Sokolic I., Ivsic T. "Analysis and measurements of settlement for heavy loaded rigid footing“, 8th European Young Geotechnical Engineers' Conference / Fratalocchi, Evelina (ur.). - Ancona: Universita Politecnica delle Marche, Associazione Geotecnica Italiana, ISSMGE, 2007.

[4] La Gatta D. P., Keller T. O. "Vertical Load Tests of Footings on Silt“, First International Conference on Case Histories in Geotechnical Engineering, Missouri University of Science and Technology.

[5] Anderson J. B., Townsend F. C., Rahelison L. "Load Testing and Settlement Prediction of Shallow Foundation“, Journal of Geotechnical and Geoenvironmental Engineering, American Society of Civil Engineers, 2007, Vol. 133, Issue. 12, pp. 1494-1502. ISSN: 1943-5606.

[6] Cajka R., Buchta V., Burkovic K., Fojtik R. "Experimental Measurement of Ground Base Plate“ Transactions of the VSB - Technical University of Ostrava, Civil Engineering Series, 2012, Vol. 12, Issue 2, pp. 1-6, ISSN: 18044824 (Online), DOI: 10.2478/v10160-0120014-6.

[7] Stolarik, M., Hrubesova, E., Pinka, "M. Dynamic Response of the Experimental
Foundation Slab - Seismic Measurement and Analysis". 15 th GeoConference on Science and Technologies in Geology, Exploration and Mining, SGEM International Multidisciplinary Scientific GeoConferences, Vol. 2, no. 1, p. 261-268. Albena, 2015.

[8] Cajka R., Krivy V., Sekanina D. "Design and Development of a Testing Device for Experimental Measurements of Foundation Slabs on the Subsoil“, Transactions of the VSB - Technical University of Ostrava, Civil Engineering Series, 2011, Vol. 11, Issue 1, pp. 1-5, ISSN: 1804-4824 (Online), DOI: 10.2478/v10160-011-0002-2.

[9] Becker, D.E. (2010) “Testing in geotechnical design“, Geotechnical Engineering, Southeast Asian geotechnical society \& association of geotechnical societies in Southeast Asia, Thailand 2010, Vol. 41, Issue 1. ISSN: 00465828.

[10] Stolarik M., Pinka M., Fojtik R. (2015) "Seismic Load due to the Jet Planes operation", 15th GeoConference on science and technologies in geology, exploration and mining, SGEM International Multidisciplinary Scientific GeoConferences, Albena, 2015,Vol. 2, no. 1, pp. 619-626. ISSN: 1314-2704.

[11] Cajka, R., Labudkova, J., Mynarcik, P. "Numerical solution of soil - foundation interaction and comparison of results with experimetal measurements“, International Journal of GEOMATE, vol. 11, no. 1, pp. 2116-2122.

[12] Lahuta, H., Hrubesova, E., Duris, L., Petrasova, T. "Behaviour Subsoil of Slab Foundation under Loading“ 15th Geoconference on Science and Technologies in Geology, Exploration and Mining, SGEM International Multidisciplinary Scientific GeoConferences, Albena, 2015. Vol. 2, no. 1, pp. 119-126. ISSN: 1314-2704.

[13] Cajka, R., Mynarcik, P., Labudkova, J. "Experimetal measurement of soil-prestressed foundation interaction“, International Journal of GEOMATE, vol. 10, no. 4, pp. 2101-2108.

Copyright (C) Int. J. of GEOMATE. All rights reserved, including the making of copies unless permission is obtained from the copyright proprietors. 